\title{
A ESFERA DA MOBILIDADE URBANA DE PRESIDENTE PRUDENTE
}

\author{
Andressa Gomes Nardi, Bianca Santos Nespoli, Wilson de Luces Fortes Machado
}

Centro Universitário Antônio Eufrásio de Toledo de Presidente Prudente, Curso de Administração, Presidente Prudente, SP. E-mail: andressanardi@hotmail.com

\section{RESUMO}

Este artigo cientifico reúne informações a respeito do tema de mobilidade urbana das cidades do país e em especial de Presidente Prudente. Analisa as formas de tratamento para a problemática do trânsito mencionadas no plano de mobilidade urbana de Presidente Prudente. O objetivo deste estudo, fundamenta-se na verificação do quanto as medidas corretivas serão efetivas no tratamento dos problemas de mobilidade. A metodologia constou de referências bibliográficas como principal forma de pesquisa, no qual o plano de mobilidade de Presidente Prudente teve uma grande participação como fonte de pesquisa. Os resultados encontrados, trata-se da aplicação dos projetos pelo plano de mobilidade com uma característica global, onde a procura por meios mais sustentáveis de se locomover passa a ser mais valorizada na sociedade atual. Por tanto, apesar dos projetos citados a serem adotados por várias cidades, implicam na aceitação das pessoas e a conscientização de todos os envolvidos.

Palavras-chave: Mobilidade Urbana, Plano de Mobilidade Urbana, Trânsito, Presidente Prudente, Cidade.

\section{THE SPHERE OF URBAN MOBILITY FOR PRUDENTE PRESIDENTE}

\begin{abstract}
This scientific paper gathers information about the urban mobility issue of the country's cities and in particular in Presidente Prudente. Analyzes forms of treatment for the problem of transit mentioned in the urban mobility plan of Presidente Prudente. The aim of this study is based on the check as the corrective measures will be effective in the treatment of mobility problems. The methodology consisted of references as the main form of research in which the Presidente Prudente mobility plan had a great participation as a source of research. The results, it is the implementation of projects by the mobility plan with a global feature, where demand for more sustainable ways of getting around becomes more valued in society today. Therefore, despite the cited projects to be adopted by several cities, imply acceptance of the people and the awareness of everyone involved.
\end{abstract}

Keywords: Urban Mobility, Urban Mobility Plan, Transit, Presidente Prudente, City. 


\section{INTRODUÇÃO}

Este artigo científico, aprofunda-se na relação que a sociedade contemporânea possui com a mobilidade urbana, em análise dos efeitos proporcionados por ela e a atuação da administração pública, conforme a lei de mobilidade, na procura por soluções sustentáveis e aplicáveis no ambiente urbanizado.

Alguns autores, referem-se à cidade como centros com ruas, prédios, trânsito, grande número de pessoas e empresas, e no presente artigo, serão apontadas informações baseadas no cotidiano das pessoas, em suas dificuldades e, principalmente, a descrição e contextualização de mobilidade urbana.

Em um contexto geral, aborda-se a lei de mobilidade urbana e o que foi gerado a partir dos planos de mobilidade urbana dos municípios. As condições que cidades planejadas possuem relacionadas ao crescimento, e como cidades não planejadas trabalham para obter o controle do trânsito caótico e extenso, consequências na maioria das cidades.

Segundo Vasconcellos (2014), o entendimento das políticas de mobilidade no Brasil necessita da compreensão de dois fatores que, simultaneamente, transformaram e proporcionaram o que se vislumbra atualmente em várias cidades brasileiras, sendo estes a urbanização acelerada e a constituição da indústria automotiva.

Prossegue autor em um contesto histórico das cidades brasileiras, onde a população urbana aumentou consideravelmente ao longo de sua história, esta condição interligada com as necessidades de educação, trabalho, indústria, comercio, saúde, lazer e outros, intensificam a necessidade de mobilidade para a realização das atividades acrescida pelo aumento de usuários. Desta forma, apresenta-se as principais causas para os pontos críticos de mobilidade.

Na cidade de Presidente Prudente, a mobilidade urbana se apresenta prejudicada por diversos fatores. "Sendo considerada um polo regional de desenvolvimento regional" (MACHIORO, 2014, p. 61), Presidente Prudente concentra uma grande frota de veículos motorizados o que leva a uma grande movimentação de pessoas e cargas pelas vias da cidade. A falta de uma otimizada rede hierarquizada para melhorar as formas de articulação viária, podem causar transtornos no trânsito e proporcionar tendências caóticas para o mesmo. Com a facilidade de acesso permitido pela rodovia Raposo Tavares, que divide a cidade em duas grandes áreas com alta concentração populacional, gera um corredor comercial nas proximidades da cidade e é fator facilitador do aumento do tráfego de pessoas oriundas de outras cidades que fazem uso dos empreendimentos comerciais. O resultado, demonstra-se por uma estrutura viária congestionada caracterizada por um trânsito denso em horários de pico.

O objetivo deste estudo está na relação entre os problemas de mobilidade levantados pelo relatório técnico do plano de mobilidade urbana de Presidente Prudente e os projetos que visão solucioná-los, com o amparo de interpretação e análise do mesmo para a efetividade das propostas referidas no presente plano de mobilidade urbana.

\section{METODOLOGIA}

A metodologia utilizada tem por fonte a pesquisa bibliografia sobre o plano de mobilidade urbana da cidade de Presidente Prudente e a nova Lei da Mobilidade Urbana. A problematização teve por foco os projetos de tratamento dos pontos críticos, o projeto da rede cicloviária integrada e o projeto calçada legal, demonstradas no planejamento da mobilidade urbana do município.

\section{RESULTADOS}

Os resultados apontaram para a questão discorrida no plano de mobilidade urbana de Presidente Prudente, sendo que, em principal contexto da cidade, apresenta-se um diagnóstico sobre a percepção da saturação das vias principais e o impacto que esta situação ocasiona para todo o cenário global da cidade. Diante da constatação, o plano se apresenta com medidas de 
combate e prevenção, tendo por objetivo tornar a mobilidade urbana visível e aplicável em respeito aos cidadãos da cidade e para melhor desenvolvimento de suas atividades econômicas.

\section{O CRESCIMENTO DAS CIDADES E A CAPACIDADE DE AQUISIÇÃO DE VEÍCULOS}

É necessário compreender o histórico de nossa sociedade, do ponto de como ela se constituiu, evoluiu e como ela é impactada por medidas de âmbito nacional e decisões locais para fornecer ideias de melhorias aos problemas vivenciados. De acordo com Vasconcellos (2014), é indispensável a análise do processo de urbanização, deve-se a recolocação de pessoas nas mais distintas localidades urbanas, aos quais passam a ter necessidades substanciais. "O processo aumentou as dimensões das cidades, fazendo crescer as distâncias e a necessidade de transporte público" (VASCONCELLOS, 2014; p.13). No caso de Presidente Prudente, nos últimos anos, o deslocamento populacional para zona norte como os bairros Cremonezi João Domingos Neto, Tapajós e Bela Vista gerou um fluxo muito acrescido de novos moradores para estas regiões.

Outro vetor da construção histórica da mobilidade se deve ao processo de constituição da indústria automobilística. O que gerou uma importante fonte de oferta de veículos para transporte individual, o que passa a disputar com o transporte público por suas carências, de acordo com Vasconcellos (2014).

A indústria automobilística obteve um grande incentivo do governo ao reduzir os impostos de produtos industrializados, ampliação do crédito e redução de juros o que facilitou ao mercado consumidor aquisição de carros novos. Segundo a pesquisa feita pelo Observatório das metrópoles no período de 2012 e 2014, enquanto a população brasileira aumentou 12,2\%, o número de veículos registrou um crescimento de $138,6 \%$. No entanto mostra apenas o número de carros registrados e não exatamente a estatística de todos os carros que circulam pelas cidades.

O governo influencia efetivamente com políticas macroeconômicas de crescimento econômico em incentivos para a indústria automobilística e construção civil. O que desencadeia outro problema ocasionado pelo alto número de veículos particular e a infraestrutura das vias no seu desenvolvimento, simultaneamente, sem um efetivo planejamento de trânsito. De acordo com Vasconcellos (2014), a problemática está ligada a inexistência de leis que, com a ausência do Estado com medidas efetivas para controle do uso do solo, o que gera a falta de controle na implantação de grandes projetos nas cidades, como centros de compra e conjuntos habitacionais, os chamados polos geradores de viagem.

Nestas condições "as cidades cresceram segundo as forças de mercado das ações de distintos grupos sociais [...]. O espaço urbano foi construído para atender aos interesses imediatos de cada grupo social [...]" (VASCONCELLOS, 2014, p. 15). Constitui-se nas necessidades de cada indivíduo congregado a grupos sociais de rendas variáveis, entre os quais, estes fatores financeiros são delimitadores para a forma de acessibilidade nas cidades.

\section{O PRINCIPIO DA LEI DA MOBILIDADE URBANA - LEI 12.587/2012}

A Lei no 12.587/2012, conhecida como Lei de Mobilidade Urbana, foi sancionada pela Presidência da República em 3 de janeiro de 2012, em que passou a vigorar 100 (cem) dias após a publicação oficial. A nova lei tem sua essência a facilitação entre o uso de diferentes modos de transporte e aprimoramento na mobilidade de pessoas e cargas nos territórios municipais. " $A$ Política Nacional de Mobilidade Urbana tem por objetivo contribuir para o acesso universal à cidade" (BRASIL. Lei no 12.587, 2012, art. 2). Nesta, há a otimização da acessibilidade de mobilidade para que se cumpra com os objetivos e diretrizes da política de desenvolvimento urbano com planejamento adequado de todas as esferas políticas para o proveito de toda a sociedade.

Nas exigências proferidas pela lei de mobilidade, o artigo 24 define que os municípios com número superior a 20.000 (vinte mil) habitantes, sendo todos os demais obrigados, a elaboração 
do plano de mobilidade urbana juntamente e integrado ao plano diretor dos municípios. "O Plano de Mobilidade Urbana deverá ser integrado ao plano diretor municipal, existente ou em elaboração, no prazo máximo de 3 (três) anos da vigência desta Lei. " (BRASIL. Lei 12.587, 2012, art. 24). De modo que, o não cumprimento deste prazo para a entrega do respectivo plano, inibe o recebimento de recursos orçamentários federais para a mobilidade urbana até o implemento das exigências da Lei.

\section{AS FASES DO PLANO DE MOBILIDADE URBANA}

$\mathrm{Na}$ face do plano de mobilidade urbana de Presidente Prudente, apresentou-se um diagnóstico da situação das condições espaciais da cidade para promover o planejamento das diretrizes nas formas de estratégias, metas e planos de ação em atendimento da veiculação de pessoas e mercadorias na cidade.

A princípio, Marchioro (2014) apresenta resultados obtidos pelo levantamento de tráfego, onde delimitou 38 (trinta e oito) pontos de contagem, dos quais apurou que em cinco anos a cidade teve um decréscimo da frota de carros em $2 \%$ (50\% em 2009), enquanto a motocicleta passou de $23 \%$ para $25 \%$ em 2014. Percebe-se a migração dos motoristas em optar por um veículo mais rápido e facilitador. Na quantidade de ônibus e micro-ônibus não apresentaram nenhuma mudança, com o mesmo percentual mínimo de $1 \%$ do total, sugerindo que não houve nenhum incentivo ou ampliação do transporte público urbano.

O plano ainda demonstra três zonas de interesse para tratamento dos problemas de tráfego, os quais são de interesse por se tratar de locais de grande movimentação de pessoas, as quais buscam saúde, educação, serviço e comércio de grande porte.

O objetivo se define no tratamento dos problemas relacionados e a aplicação de soluções que promova a humanização do trânsito e maior segurança para seus usuários, segundo o autor.

A cidade de Presidente Prudente, para o planejamento e execução do plano, foi subdividida em seis regiões para facilitar a montagem da estratégia de tratamento dos pontos críticos. Desta forma, o tratamento possui maior compatibilidade com a região.

Um dos pontos de destaque seria a implantação do sistema binário, e segundo Marchioro (2014), são necessários para disciplinar o trânsito e minimizar conflitos junto aos cruzamentos. Além deste, a revisão geométrica em pontos críticos.

O plano de mobilidade urbana de Presidente Prudente, apresenta ainda dois projetos de destaque para adequação da mobilidade na cidade no qual se intitulam-se como Projeto da Rede Cicloviária Integrada e Projeto Calçada Legal.

Compatibilizado com a Política Nacional de Mobilidade Urbana Sustentável, o projeto referido ao uso de bicicletas como meio de transporte habitual, esporte ou lazer tem o objetivo integrar a bicicleta aos outros modais de transporte urbano. No entanto, para a população confronta esta ideia pelas condições estruturais das vias, segurança e falta de sinalização, além de questões climática. Para Vasconcellos (2014), no Brasil há uma grande variação na quantidade de ciclistas no uso da bicicleta como modo de transporte urbano. Sendo muito condicionado ao tipo topográfico (sistema viário) e condicionantes de trânsito (velocidade das vias e veículos pesados).

Cidades que estão implantando as ciclovias encontram aprovadores e desaprovadores desta ideia globalizada, como apresenta o Mobilize Brasil (2015) nos pontos e contrapontos sobre o plano cicloviário de $400 \mathrm{Km}$, de acordo com a Companhia de Engenharia de Tráfego (CET) da cidade de São Paulo. Segundo articuladores de opinião, as ciclovias de São Paulo apresentam problemas de segurança, estruturais e de sinalização, além da manutenção destas vias de transporte não motorizado.

O desenvolvimento do projeto da rede cicloviária apresente diretrizes básicas determinadas pelo Ministério das Cidades para motivação dos usuários, sendo elas a segurança, atratividade, conforto, coerência na estrutura e rotas rápidas. 
Para o projeto das calçadas, o interesse é em motivar os deslocamentos a pé pela promoção do espaço público convidativo e atrativo. O projeto conta com o desenvolvimento da proteção a todos os cidadãos, proporcionando estrutura, segurança e arborização adequada para o uso das calçadas e acessibilidade.

Como indicado a princípio, temos a clara revelação de que o transporte coletivo não apresentou ampliação e o uso dos ônibus como transporte público estagnou-se em nossa região. Por outro lado, vemos em Londrina-PR, um esforço público para a melhoria desse tipo de transporte, onde instauraram um programa de transporte com a aquisição de superbus, veículos articulados com cerca de 19 metros de comprimento e que disponibilizam de toda a acessibilidade e conforto para os mais de 80 mil usuários atendidos diariamente.

\section{CONCLUSÃO}

Conforme o desenvolvimento da pesquisa, as análises dos pontos críticos a serem considerados sobre a observância favorável da aplicação regulamentada da Lei 12.587/2012; indica resultados positivos diante o avanço da formalização do tratamento para melhorias da mobilidade urbana. $O$ ato prático de fiscalização da referida lei, com a exigência de planos de mobilidade urbana pelos municípios, se torna condicionado ao recebimento dos recursos orçamentários federais, em que por consequência do não cumprimento das exigências da legislação o município recebe tal penalidade financeira.

Os planejamentos estruturados pelos municípios podem variar de acordo com a necessidade e a urgência de medidas a serem adotadas para melhor impacto ao trânsito caótico. No entanto, os planos têm em comum aplicação de alguns projetos, tais como: infraestrutura de escoamento de vias congestionadas, construção de projetos de calçadas seguras e acessíveis aos pedestres, adequação do transporte público e implantação ao aumento de ciclovias, sendo o motivo para os projetos coincidirem a incidência de necessidade que as pessoas têm de deslocamento com agilidade, segurança e conforto.

Aprecia-se a forma de promover a sustentabilidade nas cidades, procurando estimular serviços de qualidade em favorecimento de todos. Promover um trânsito saudável em todos os seus aspectos como, redução da poluição e de ruído, integração com os mais diversos modos de transportes, sendo esses motorizados ou não, para que não exista discórdia no trânsito e de certa forma aprimorar o que já está presente em nosso cotidiano como o uso do transporte público coletivo.

Além dos fatos citados, há necessidade de uma política de implementação que passe a conscientizar a população no geral para aplicação dos projetos que sustentem a mobilidade, pois não haverá êxito enquanto houver discordância por parte dos usuários.

Para os utilitários dos meios de transporte privado e público, aponta-se necessidades do aumento das linhas viárias de circulares na cidade, assim como, a implantação de vans e microônibus legalizadas para acesso periférico ao centro, considerando que o aumento do número de vans para mais destinos, implicariam consequentemente, na diminuição do congestionamento muitas vezes ocasionado pela lentidão dos ônibus, e aumentaria a agilidade para os destinos em comuns, como por exemplo ônibus que circulam com lotação de um destino fixo a outro. Essa melhoria dos transportes coletivos, com a participação dos órgãos públicos em parcerias com entidades privadas para que de fato conquistássemos os resultados esperados.

Em suma, o impacto que a lei de mobilidade oferece para toda a estrutura urbana tem um caráter muito positivo ao que passa a dispor de diretrizes e objetivos que integram cidades em um modelo que preza pela acessibilidade e cidadania. No entanto, é de grande importância que a aplicação dos planos sejam verdadeiramente praticados de forma integra e com a responsabilidade que cabe ao poder público em favor do bem estar de todos. 


\section{REFERÊNCIAS}

BHTRANS. Política Municipal de Incentivo ao Uso de Bicicletas Ganha Projeto. Disponível em <http://www.bhtrans.pbh.gov.br/portal/page/portal/portalpublico/Temas/Noticias/projeto\%20cic lovia>. Acesso em: 07 ago. 2016.

BRASIL. Congresso Nacional. Lei de Mobilidade Urbana. Lei no 12.587 de 03 de janeiro de 2012. Institui as diretrizes da Política Nacional de Mobilidade Urbana; revoga dispositivos dos DecretosLeis nos 3.326, de 3 de junho de 1941, e 5.405, de 13 de abril de 1943, da Consolidação das Leis do Trabalho (CLT), aprovada pelo Decreto-Lei no 5.452, de 1 o de maio de 1943, e das Leis nos 5.917, de 10 de setembro de 1973, e 6.261, de 14 de novembro de 1975; e dá outras providências. Diário Oficial da União, Brasília, DF, 03 jan. 2012. Disponível em: http://www.planalto.gov.br/ccivil_03/_ato2011-2014/2012/lei//12587.htm\#art28. Acesso em: 28 jul. 2016.

CACIOLI, Natália. Teste das ciclovias de São Paulo. Disponível em: <http://infograficos.estadao.com.br/public/cidades/ciclovias/> Acesso em: 06 ago. 2016.

DIAS, DU. Pontos e contrapontos sobre o plano cicloviário da cidade de São Paulo. Disponível em: <http://www.mobilize.org.br/noticias/7777/pontos-e-contrapontos-sobre-o-plano-cicloviario-dacidade-de-sao-paulo.html> Acesso em: 07 ago. 2016.

HEDLER, A.P.; OLIVEIRA, R.; ACCORSI, A. Superbus começa a funcionar em Londrina. Disponível em:

<http://www.londrina.pr.gov.br/index.php?option=com_content\&view=article\&id=24434:superb us-comeca-a-funcionar-em-londrina\&catid=203:noticias-mobilidade\&/temid=2028> Acesso em: 07 ago. 2016.

MARCHIORO Edson. Plano de Mobilidade Urbana de Presidente Prudente. Presidente Prudente; 2014.

PENA, Rodolfo F. Alves. Mobilidade urbana no Brasil. Disponível em $<$ http://brasilescola.uol.com.br/geografia/mobilidade-urbana-no-brasil.htm>. Acesso em: 13 de ago. 2016.

VASCONCELLOS, E. Alcântara. Mobilidade urbana e cidadania. Rio de Janeiro: Senac Nacional, 2012.

VASCONCELLOS, E. Alcântara. Políticas de transporte no Brasil: A Construção da Mobilidade Excludente. 1. ed. Barueri: Editora Monole, 2014. 